\title{
Программное приложение для термального моделирования интрузий
}

\section{Степенщиков Д.Г., Грошев Н.Ю.}

Геологический институт КНЦ РАН, Anamumbl, nikolaygroshev@gmail.com

Аннотация. В статье приводится описание программного приложения, разработанного для одномерного моделирования теплообмена между различными интрузивными телами и рамой.

Ключевые слова: термальное моделирование; расслоенные интрузии; остывание интрузивных тел; сульфидное оруденение; контактовый тип.

\section{The application software for thermal modeling of intrusions}

Stepenshchikov D.G., Groshev N.Yu.

Geological institute KSC RAS, Apatity,nikolaygroshev@gmail.com

\begin{abstract}
The article describes the application software for one-dimensional modeling of heat transfer between various intrusive bodies and their frame.

Key words: thermal modeling; layered intrusions; cooling of intrusive bodies; sulfide mineralization; contact-style.
\end{abstract}

Предпосылкой разработки приложения для термального моделирования явилась гипотеза о критическом значении температурного фактора при формировании контактовых месторождений элементов платиновой группы в расслоенных интрузиях (Karykowski et al., 2018). Такие месторождения приурочены к мафит-ультрамафитовым расслоенным комплексам, которые, как правило, были образованы в результате нескольких внедрений магмы. Согласно вышеупомянутой гипотезе, температурное влияние ранних интрузий создает условия для значительного частичного плавления пород рамы при последующих внедрениях, что за счет притока флюида снижает вязкость магмы и, в конечном счете, способствует эффективному концентрированию сульфидов вблизи дна магматической камеры. В зависимости от особенностей строения конкретного месторождения, с помощью моделирования можно уточнить сценарий его формирования, оценив мощность зоны частичного плавления и временной разрыв между интрузивными фазами (Грошев, Степенщиков, 2019).

Основой вычислений является одномерное уравнение теплопроводности, которое методом конечных разностей сводится к реккурентному соотношению:

$$
\frac{d T}{d t}=k \frac{\partial^{2} T}{\partial x^{2}} \Rightarrow T_{i}^{n+1}=T_{i}^{n}+k \Delta t\left(\frac{T_{i+1}^{n}-2 T_{i}^{n}+T_{i-1}^{n}}{(\Delta x)^{2}}\right),
$$

где $T_{i}^{n}-$ температура на глубине $i \times \Delta x$ м через $n \times \Delta t$ лет. Подробный вывод уравнения приведён в (Karykowski et al., 2018). Вся моделируемая толща мощностью $H$ (м) разбивается на элементарные слои толщиной $\Delta x$ (м), в каждом из которых температура принимается постоянной. Начальное температурное распределение по всей толще задаётся температурой на поверхности $T_{0}\left({ }^{\circ} \mathrm{C}\right)$ и геотермическим градиентом $\Gamma\left({ }^{\circ} \mathrm{C} / \mathrm{M}\right)$, линейно повышающим температуру с увеличением глубины. Формально распределение температуры можно представить в виде таблицы с числом строк $H / \Delta x$, в $i$-ой ячейке первого столбца которой записывается значение $T_{0}+i \times \Delta x \times \Gamma(i=0 . . H / \Delta x)$. Для вычислений используется второй столбец таблицы, в котором заданы первый и последний элемент - температура на поверхности, постоянно равная $T_{0}$ (первый элемент столбца) и температура на максимальной глубине $T_{H}=T_{0}+H \times \Gamma$ (последний элемент столбца). Вычисления новых значений температуры через интервал времени $\Delta t$ осуществляются по реккурентной формуле (1) последовательно сверху вниз, начиная со второго элемента столбца до предпоследнего (рис. 1). Затем весь второй столбец копируется в первый и процесс повторяется.

Интрузивные тела задаются четырьмя числами: границей кровли (м), мощностью (м), температурой $\left({ }^{\circ} \mathrm{C}\right)$ и моментом внедрения (лет). Их может быть задано любое количество как в один и тот 


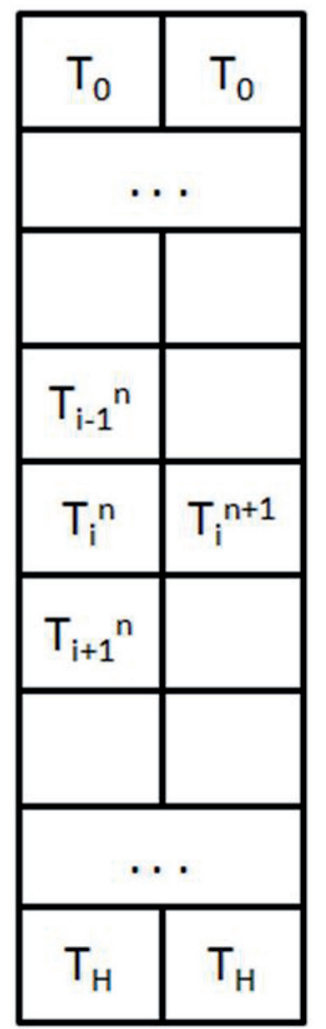

Рис. 1. Схема расчёта новых значений температуры.

Fig. 1. Scheme of calculating of new temperature points. же, так и в разные моменты времени. Для каждого тела данные записываются одной строкой в окне 1 интерфейса приложения (рис. 2). В ходе моделирования происходит постоянная сверка текущего времени с заданными для интрузивов моментами внедрения. В случае совпадения времени с каким-либо моментом, слоям толщи, соответствующим расположению интрузива, мгновенно присваивается его температура, и затем процедура расчёта продолжается.

Для отслеживания динамики картины, необходимо задать список интересующих глубин (окно 2, рис. 2) и времени контроля температуры (окно 3, рис. 2). И глубины, и временные моменты при считывании данных автоматически упорядочиваются по возрастанию и переотображаются в соответствующих окнах. На их основе создаётся таблица, в которую записываются основные результаты моделирования - температура толщи на заданных глубинах в заданные моменты времени (окно 5, рис. 2). Таблица может быть сохранена в формате XLS для Microsoft Excel. Результаты моделирования для указанных временных отсечек из окна 3, графически ото-

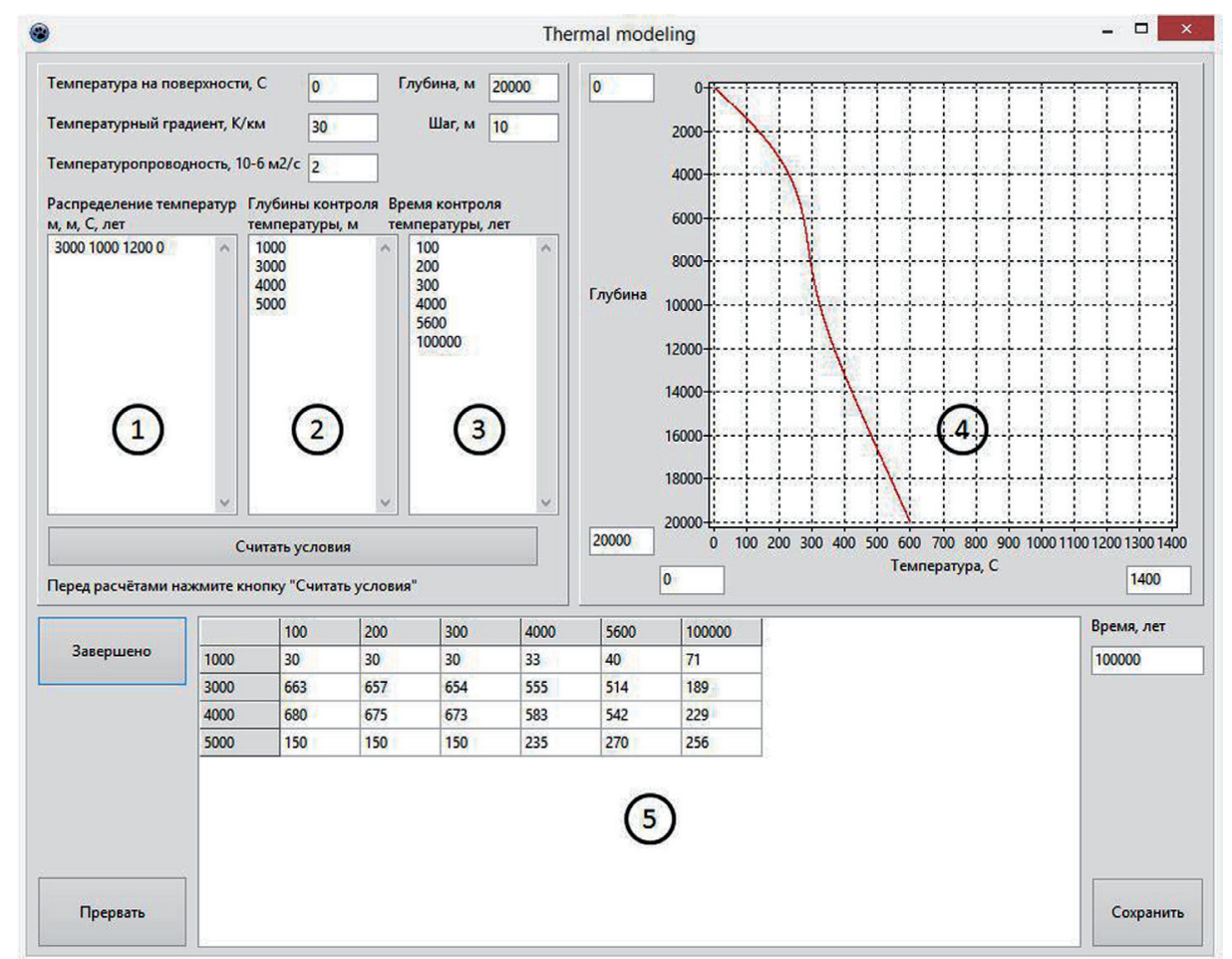

Рис. 2. Интерфейс программы. 1 - параметры интрузивов, 2 - глубины контроля температуры, 3 - моменты контроля температуры, 4 - график «температура-глубина», 5 - таблица температур для заданных глубин и моментов времени (окна 2 и 3).

Fig. 2. The program interface. 1 - parameters of intrusions, 2 - temperature control depths, 3 -temperature control points, 4 - temperature-depth graph, 5 - temperature table for given depths and time points (windows 2 and 3 ). 
бражаются в окне 4. Данное окно может быть также полезно для тестирования корректности заданных параметров интрузивов. Ввиду того, что время моделирования ничем не ограничено сверху и может привести к длительной работе программы, предусмотрен досрочный останов её выполнения без сохранения точки останова, то есть после прерывания вычисления начнутся заново.

В ходе реализации программы были выяснены следующие особенности модели.

1) Вариация геотермального градиента в толще не имеет смысла (например, $20^{\circ} \mathrm{C} /$ км до половины глубины, а затем $30^{\circ} \mathrm{C} /$ км ниже), поскольку в стационарном случае $(d T / d t=0)$ распределение температуры во всей толще будет подчиняться линейной зависимости:

$$
\frac{\partial^{2} T}{d x^{2}}=0 \Rightarrow T=A x+B
$$

Иными словами, изначально заданное в виде ломаной вдоль всей толщи температурное распределение при стремлении к равновесному режиму вырождается в прямую линию.

2) Фактически рассеиваемое магматическое тепло уходит через крайние точки толщи - поверхность и самый глубокий элементарный слой. И, если рассеивание тепла на поверхности можно считать обоснованным, то на глубине процесс теплообмена обрывается - последний слой всегда имеет постоянную температуру и не поглощает поступающую сверху тепловую энергию. При малых $H$ и достаточно мощных и/или горячих интрузиях этот граничный эффект может привести к погрешностям.

3) Температура элементарного слоя до очередного момента внедрения не учитывается - модель в принципе не приспособлена «раздвигать» слои толщи, освобождая место для магмы. Вместо этого элементарные слои, соответствующие глубине залегания и мощности интрузии, сами «становятся магмой», мгновенно нагреваясь до её температуры.

4) Коэффициент температуропроводности ( $k$ в формуле (1)), согласно модели и критерию стабильности фон Неймана связан с $\Delta x$ и $\Delta t$ соотношением $\Delta x^{2}=4 k \Delta t$. При варьировании $k$ в толще с необходимостью должны меняться либо толщина элементарного слоя, либо шаг времени, что в рамках данной модели невозможно. Зависимость величины $k$, например, от температуры, показана в (Гаджиев и др., 2014). Примечательно, что в самой рекуррентной формуле (1) все эти три величины взаимоуничтожаются, неявно присутствуя только в индексах $T$ :

$$
T_{i}^{n+1}=T_{i}^{n}+k \Delta t\left(\frac{T_{i+1}^{n}-2 T_{i}^{n}+T_{i-1}^{n}}{(\Delta x)^{2}}\right)=T_{i}^{n}+k \Delta t\left(\frac{T_{i+1}^{n}-2 T_{i}^{n}+T_{i-1}^{n}}{4 k \Delta t}\right)=\frac{T_{i+1}^{n}+2 T_{i}^{n}+T_{i-1}^{n}}{4} .
$$

Работа выполнена в рамках темы НИР №0226-2019-0053.

\section{Литература}

1. Karykowski B. T., Maier W. D., Groshev N. Y., Barnes S. J., Pripachkin P. V., McDonald I., Savard D. Critical Controls on the Formation of Contact-Style PGE-Ni-Cu Mineralization: Evidence from the Paleoproterozoic Monchegorsk Complex, Kola Region, Russia // Economic Geology. 2018. 113(4). P. 911-935. DOI: 10.5382/ econgeo.2018.4576.

2. Гаджиев Г.Г., Рамазанова А.Э., Эмиров С.Н. Теплофизические свойства гранита при высоких давлениях и температурах // Известия РАН. Серия физическая. 2014. Т. 78. № 4. С. 452-454.

3. Грошев Н.Ю., Степенщиков Д.Г. Термальная история базального контакта в расслоенном интрузиве Фёдоровой тундры, Кольский регион, Россия // Труды Ферсмановской научной сессии ГИ КНЦ РАН. 2019. 16. (этот сборник). 